\title{
Explorando História da Ciência na Amazônia: O Museu Interativo da Física
}

\author{
Exploring History of Science in Amazonia: The Physics Interactive Museum \\ Jocasta Caldas, Marcelo C. de Lima, Luís C. B. Crispino* \\ Faculdade de Física, Universidade Federal do Pará, Belém, PA, Brasil
}

Recebido em 27 de abril de 2016. Aceito em 17 de junho de 2016

\begin{abstract}
No ano de 2008, professores e alunos da Faculdade de Física da Universidade Federal do Pará realizaram uma iniciativa pioneira para divulgação de História da Ciência na Amazônia brasileira. Esta iniciativa, denominada Museu Interativo da Física, passou a atuar em parceria com a comunidade amazônida, suas organizações governamentais, outras universidades, escolas municipais e estaduais do Estado do Pará com o intuito de colaborar com o aumento da qualidade da educação científica na região. Neste artigo, abordamos as atividades do Museu Interativo da Física e o impacto da sua participação na divulgação de História da Ciência na Amazônia brasileira.

Palavras-chave: História da Ciência, Museu, Física.
\end{abstract}

In 2008, professors and students of the Physics Department of the Federal University of Pará realized a pioneering initiative for the dissemination of the History of Science in the Brazilian Amazonia. This initiative, named Physics Interactive Museum, started to act in partnership with the Amazonian community, its governmental organizations, other universities, state and municipal schools of the Pará State aiming to collaborate with the enhancement of the quality of science education in the region. We present the activities of the Physics Interactive Museum and the impact of its participation in the dissemination of History of Science in the Brazilian Amazonia.

Keywords: History of Science, Museum, Physics.

\section{Introdução}

Práticas de difusão e popularizacão de ciência e tecnologia têm sido amplamente utilizadas mundo afora. Em diversos países, como França [1], Espanha [2], Polônia [3] e Argentina [4], grandes museus e centros de ciência promovem exposições que incentivam a busca pelo conhecimento científico nos mais variados graus de complexidade. Estes ambientes de ensino informal tornam-se, cada vez mais, elementos indispensáveis para a alfabetização científica seja ela prática, cívica ou cultural - adquirida no ensino formal [5]. Vinculados a iniciativas públicas e/ou privadas, muitos destes museus e centros de ciência visam envolver a população em atividades que relacionam tanto conceitos básicos sobre ciência, quanto descobertas científicas. No Brasil, a multi-

*Endereço de correspondência: crispino@ufpa.br plicação destes ambientes informais ainda parece tímida quando comparada a países mais desenvolvidos econômica e socialmente. Na Amazônia brasileira destacam-se, por exemplo, o Museu Paraense Emílio Goeldi [6], inicialmente denominado Museu Paraense, instalado em 1871 [7], e o Museu da Amazônia (MUSA) [8], fundado em 2009. Ambos desenvolvem diversas atividades, incluindo difusão e popularização, relacionadas às ciências naturais e humanas, na Amazônia.

Uma alternativa para suprir a carência de museus e centros de ciência para divulgação científica é a parceria com as universidades. Iniciativas como centros de ciência vinculados às universidades incentivam e ratificam o apoio da Academia para a educação científica. Como exemplos bem sucedidos, podemos citar iniciativas nas mais diversas localidades brasileiras, como a Estação Ciência [9], em São Paulo, 
a Seara da Ciência [10], em Fortaleza, e a Casa da Física [11], em Manaus. Além de contribuir para o aprimoramento da educação básica, por meio de parcerias com professores de escolas de ensino básico e técnico, a implantação de museus e centros de ciência nas universidades promove uma integração com os estudantes do ensino superior, proporcionando oportunidades de atuação e o aprimoramento de suas habilidades e competências. A inserção progressiva de estudantes de licenciaturas como mediadores em espaços não formais de ensino incentiva o contato com metodologias de aprendizagem diferenciadas. Muitos destes estudantes adquirem o primeiro contato com a docência nestes espaços e aprendem a construir suas próprias abordagens para o ensino formal a partir destas experiências.

Entre as metodologias de aprendizagem utilizadas em museus e centros de ciência, a experimentação adquire cada vez mais destaque. A interação do público com o experimento é fundamental, desde que assistida por um mediador. Com a manipulação do equipamento, o visitante tende a desenvolver suas próprias associações a partir, por exemplo, da recordação de experiências acumuladas em seu diaa-dia.

As ações educativas realizadas em museus e centros de ciência também contribuem para promover a transdisciplinaridade do conhecimento. A associação de conteúdos das ciências exatas e das ciências humanas, que são geralmente vistos de forma compartimentada desde o ensino fundamental, carrega em si o objetivo de apresentar aspectos transdisciplinares durante a construção social e humana da ciência. Por exemplo, a abordagem da História para a compreensão da evolução científica e tecnológica possibilita a apresentação da ciência de forma contextualizada e com o caráter real de seu desenvolvimento, por vezes errático e cheio de reveses.

Gradualmente, museus e centros de ciência têm surgido na Amazônia brasileira e evoluído na tentativa de suprir a demanda por ações alternativas em educação na região. Com o objetivo de divulgar ciência, especificamente a Física, para um público imerso em uma cultura rica e diversificada, foi criado o Museu Interativo da Física (MINF) [12 da Universidade Federal do Pará (UFPA), como uma iniciativa de extensão universitária que promove ações educativas que visam ensinar Física, incorporando a História da Ciência e a interatividade com réplicas históricas como estratégias para alcançar esse fim.

Neste artigo abordaremos as estratégias, as atividades, as experiências e as perspectivas do MINF/ UFPA para o desenvolvimento da educação científica na região amazônica.

\section{O Museu Interativo da Física}

Em março de 2008, uma equipe de professores e alunos da Faculdade de Física da UFPA (Fig. 1) decidiu iniciar um projeto de extensão universitária para divulgação científica em Física e História da Ciência na Amazônia brasileira.

Impulsionados pela aquisicão de réplicas interativas de equipamentos históricos no ano de 2007, e utilizando os moldes de outra iniciativa de extensão universitária para divulgação científica no Pará, o Laboratório de Demonstrações da UFPA [13], o MINF/UFPA surgiu como a primeira iniciativa na região com o ideal de ensino, divulgação e popularização da História da Ciência a partir de abordagens experimentais.

As atividades iniciais do MINF/UFPA foram baseadas em apresentações internas sobre os experimentos históricos do acervo, para estudantes das escolas da rede pública de ensino de Belém, capital do Estado do Pará, e foram ampliadas progressivamente. Por experimentos históricos entendemos aqueles originalmente concebidos e realizados por cientistas que iniciaram algum campo de investigação das ciências físicas ou que tiveram caráter seminal no desenvolvimento do conhecimento. Estes experimentos possibilitam que nos transportemos ao momento em que o problema se colocou, diante do cientista

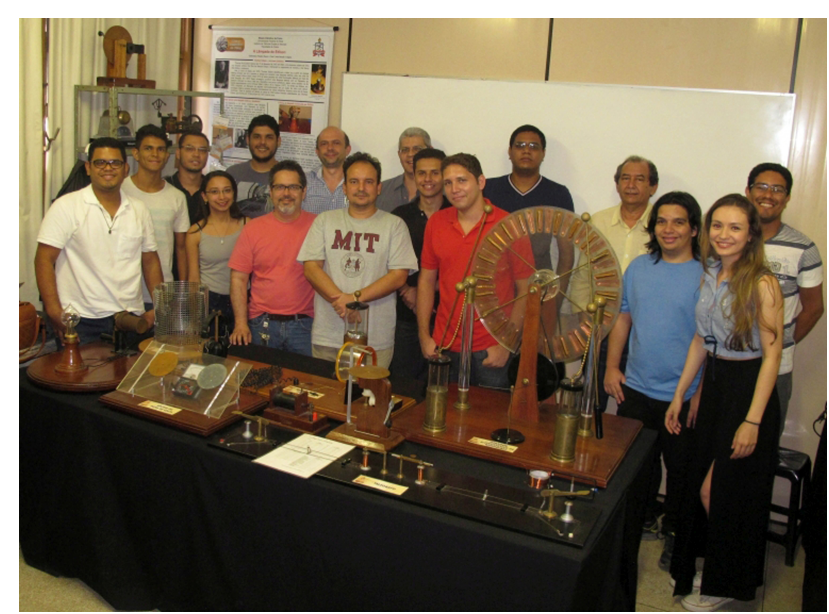

Figura 1: Equipe do MINF/UFPA em 2015. 
ou da comunidade científica, quando o experimento objetivou, à época, trazer algum esclarecimento, melhor estabelecer a fenomenologia, ou mesmo testar premissas acerca do fenômeno estudado.

As atividades do MINF/UFPA começaram a ser realizadas como um suporte para educação básica, técnica e superior no Estado do Pará, visando despertar a curiosidade científica por meio da demonstração monitorada e interativa com os experimentos históricos, do desenvolvimento de materiais de divulgação científica e de apresentações de seminários, de oficinas e de minicursos.

O trabalho desenvolvido pelo MINF/UFPA tem como principal objetivo incentivar a construção conceitual sobre temas científicos e tecnológicos a partir da apresentação dos conteúdos da ciência e sua história, com ênfase em Física. As conexões com os períodos sócio-históricos em que diversas teorias, experiências e equipamentos foram desenvolvidos são apresentadas com o intuito de contextualizar a Física na universalidade do conhecimento humano. O MINF/UFPA utiliza a abordagem sócio-histórica como ferramenta de apoio à compreensão do desenvolvimento do conhecimento científico, visando estimular os debates, superar a mera repetição de equações e humanizar a ciência. Dessa forma, o ensino de ciências tende a ser beneficiado pela transdisciplinaridade, o que, integrando a história e a filosofia em seus conteúdos, possibilita a aproximação de diversos temas [14], como a ética na pesquisa, dado o reflexo oriundo de determinados avanços científicos e suas influências em mudanças ambientais, e questões relacionadas ao feminismo [15, dada uma notável ausência participativa de mulheres no decorrer das descobertas científicas.

Além disso, o MINF/UFPA utiliza a abordagem experimental associada simultaneamente à abordagem sócio-histórica em uma linha construtivista baseada na assimilação de conceitos de acordo com a estrutura do conhecimento prévio, construindo e reconstruindo conceitos e concepções a partir de diálogo, ação e reflexão 16. Os recursos de interatividade adotados nas abordagens visam envolver as diversas características observadas no público, como a curiosidade, a ludicidade, a introspecção e a linguagem, como elementos da construção de um ambiente harmônico e fértil para novas concepções [17].

\subsection{Acervo do MINF/UFPA}

Em museus e centros de ciência é possível observar o papel dos equipamentos interativos utilizados no processo de ensino e de aprendizagem. O MINF/UFPA incorpora tanto elementos e abordagens de museus, quanto de centros de ciência. Em um espaço que visa a divulgação e a popularização da ciência por meio do resgate de um ambiente histórico e da interatividade, os objetos são apresentados como um vínculo entre o passado e o presente. Assim, com a intenção de estabelecer o acesso do público até mesmo ao chamado patrimônio intangível [18, objetos com características museológicas são expostos para interação monitorada, levando os visitantes à experiência única que é colocar a ciência em prática de forma independente.

O acervo permanente do MINF/UFPA é constituído por equipamentos fabricados para abordagens históricas, experimentais e interativas com o público, entre os quais podemos citar: Pêndulo Eletrostático, Eletroscópio de Folhas (Fig. 2a), Garrafa de Leyden, Gaiola de Faraday, Máquina de Wimshurst, Gerador de Van de Graaff, Síntese da Pilha de Volta, Prisma de Newton, Máquina a Vapor, Modelo de Telégrafo (Fig. 2b), Modelo de Telefone, Lâmpada de Edison, Modelo de Motor Elétrico e Bobina de Tesla. Estes equipamentos, além de experiências envolvendo material de baixo custo, são utilizados nas demonstrações em apresentações internas e externas no MINF/UFPA. A maioria destes experimentos históricos e científicos foi adquirida da empresa Ciência Prima [19, especializada na construção de equipamentos para uso educacional. Desta forma, os equipamentos disponíveis no MINF/UFPA possuem basicamente a mesma qualidade encontrada nos grandes centros de ciência do país, como,

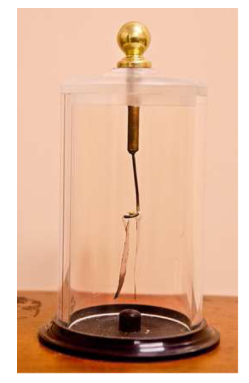

(a)



(b)
Figura 2: Alguns equipamentos do MINF/UFPA. (a) Eletroscópio de Folhas e (b) detalhe do Modelo de Telégrafo. Fotografias de Manoel J. da S. Neto. 
por exemplo, o Catavento Cultural [20], em São Paulo.

Dentre os equipamentos históricos que despertam grande fascínio nos visitantes no MINF/UFPA, podemos citar a Síntese da Pilha de Volta (Fig. 3) e a Máquina de Wimshurst (Fig. 4).

Desenvolvida pelo físico e químico italiano Alessandro Volta (1745 - 1827), a Pilha de Volta foi o primeiro dispositivo capaz de gerar uma corrente elétrica contínua por meio de reações eletroquímicas. Foi originalmente constituída pelo empilhamento de discos de zinco e cobre separados por pedaços de tecido umedecidos por água salgada [21] (Fig. 3a). Algumas experiências fundamentais para o desenvolvimento da teoria eletromagnética foram possibilitadas com o advento da pilha elétrica. Cientistas como o físico e químico dinamarquês Hans Christian Ørsted (1777 - 1851), responsável pela descoberta da relação entre eletricidade e magnetismo, o físico e matemático francês André-Marie Ampère (1775 - 1836), em suas experiências sobre fenômenos eletrodinâmicos, e o físico e químico britânico Michael Faraday (1791 - 1867), em seus estudos sobre a indução eletromagnética, utilizavam as pilhas elétricas para gerar correntes elétricas contínuas através dos circuitos de seus experimentos 22,23 . A Síntese da Pilha de Volta do acervo de experimentos do MINF/UFPA (Fig. 3b), fabricada pela Ciência Prima [19], é constituída de uma única célula voltaica na qual o público que interage com o aparato é parte da própria célula, desempenhando o papel do meio úmido. O aparato é utilizado para ilustrar os conceitos de conversão de energia, reações eletroquímicas, diferença entre propriedades de materiais metálicos, entre outros.

Os fenômenos observados no funcionamento da Máquina Eletrostática de Wimshurst, além de sua ro-

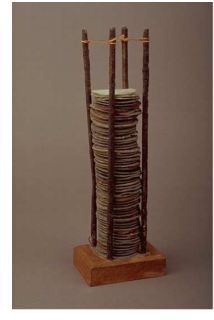

(a)

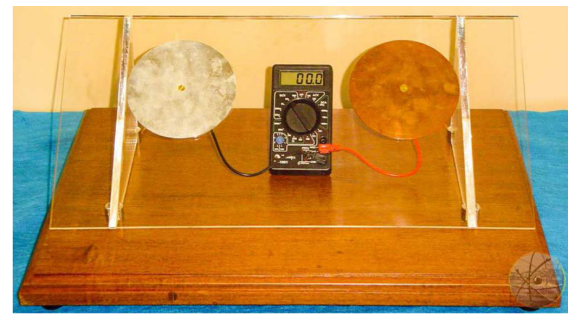

(b)
Figura 3: (a) Pilha de Volta exposta no Tempio Voltiano, em Como, na Itália [24]. (Cortesia do Tempio Voltiano.) (b) Síntese da Pilha de Volta do acervo de experimentos do MINF/UFPA.

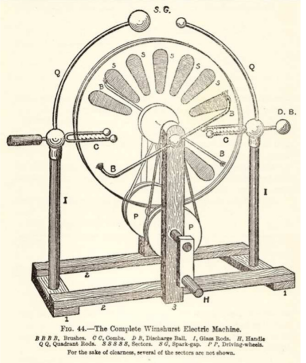

(a)

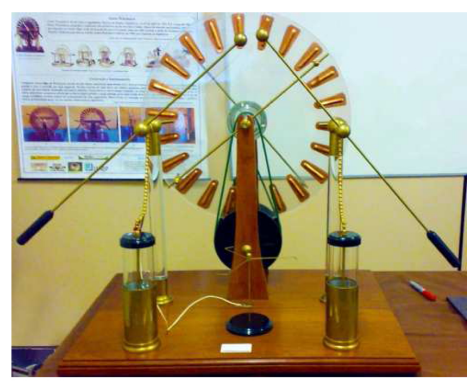

(b)
Figura 4: (a) Ilustração de uma Máquina de Wimshurst de 1929 [25]. (b) Máquina de Wimshurst do acervo de experimentos do MINF/UFPA.

bustez e notável aparência, despertam a curiosidade do público do MINF/UFPA. Primeiramente descrita em 1883 pelo seu inventor, o engenheiro britânico James Wimshurst (1832 - 1903), a máquina é um gerador eletrostático de altas voltagens constituído por dois discos de vidro idênticos que giram em sentidos opostos ao redor de um mesmo eixo com um certo afastamento (Fig. 4 4 ). Os discos possuem pequenas placas metálicas igualmente espaçadas [26]. A Máquina Eletrostática de Wimshurst é conhecida por ser uma das mais eficientes máquinas eletrostáticas de indução e funciona por meio da separação das cargas elétricas através de indução eletrostática 27]. Apesar da grande utilidade para demonstrações, sua utilidade prática foi inicialmente curta, tendo seu uso sido resgatado após a descoberta dos raios X, em 1895. Porém, com os avanços tecnológicos, foi rapidamente substituída por outras fontes de energia. A Máquina Eletrostática de Wimshurst do acervo de experimentos do MINF/ UFPA (Fig. 4 b), também fabricada pela Ciência Prima 19, é uma réplica do equipamento desenvolvido por Wimshurst e conta com pequenas modificações nos materiais utilizados e na aparência.

\subsection{Réplicas de Experimentos Históricos construídas pelo MINF/UFPA}

Uma das vertentes das atividades do MINF/UFPA é a ampliação de seu acervo por meio da confecção própria de réplicas de experimentos históricos. Esta prática tem possibilitado ao monitor do MINF/UFPA o enfrentamento de diversas dificuldades técnicas que precisam ser devidamente avaliadas e testadas, desde a concepção e projeto, a fim de assegurar o funcionamento do experimento a contento, isto é, 
revelando de forma inequívoca o efeito que se deseja exibir.

Dentre as réplicas confeccionadas [28], podemos citar o Disco de Arago (Fig. 5) e o Dínamo de Disco (Fig. 6).

O Disco de Arago foi concebido originalmente pelo físico, astrônomo e político francês François Arago (1786 - 1853) e apresentado à Academia de Ciências de Paris em 1825 [29], na sequência de inúmeras investigações inspiradas e decorridas da descoberta do eletromagnetismo, isto é, da ação magnética da corrente elétrica, realizada por Ørsted, em 1820 [30]. No Disco de Arago, uma haste imantada é suspensa horizontalmente sobre um disco de cobre (Fig. 5a). Ao se fazer girar o disco observa-se que a haste imantada acompanha o movimento rotatório do disco, o que foi originalmente interpretado, por Arago, como um "magnetismo de rotação" induzido no disco de cobre. Este fenômeno viria a ser corretamente interpretado por Faraday, em 1831, após a descoberta da indução eletromagnética. O "magnetismo de rotação" é consequência das correntes induzidas surgidas sobre o disco de cobre devido ao movimento deste na presença de um corpo magnético (a haste). Tais

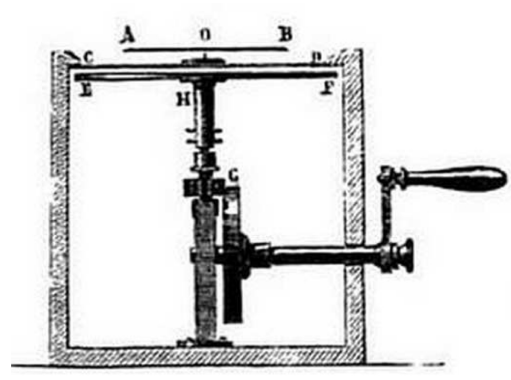

(a)

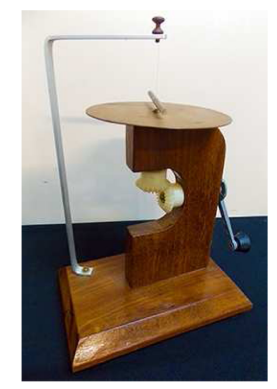

(b)
Figura 5: (a) llustração em vista lateral do Disco de Arago [31]. (b) Réplica do Disco de Arago confeccionado pelo MINF/UFPA.

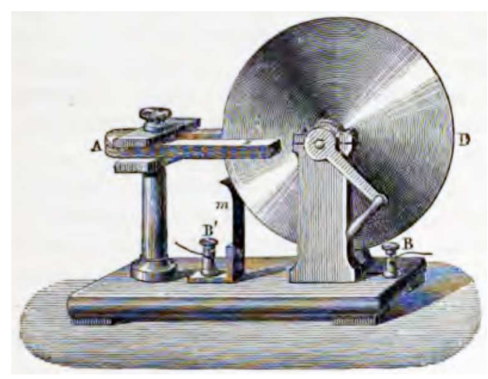

(a)

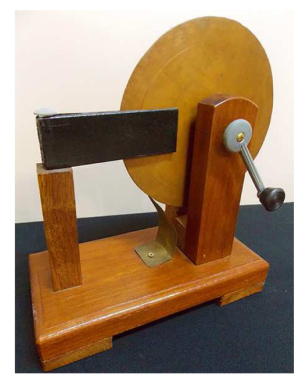

(b)
Figura 6: (a) Ilustração do Dínamo de Disco de Faraday [32]. (b) Réplica do Dínamo de Disco confeccionado pelo MINF/UFPA. correntes, como Faraday (e, independentemente, o físico estoniano Heinrich Lenz, 1804 - 1865) estabeleceu, se opõem à variação de fluxo magnético em uma porção qualquer do sistema. No caso em questão, isto significa opor-se ao movimento relativo entre o disco e a haste. Estando o disco mantido em movimento pelo agente externo e a haste livre para girar, ela então passa a acompanhar o disco em rotação. A compreensão do Disco de Arago levou Faraday à construção do primeiro dínamo da história: o Dínamo de Disco, de Faraday. Mantendo um disco de cobre em rotação na presença de um corpo magnético (Fig. 6a), Faraday coletou a corrente induzida em diversas possíveis configurações do sistema [33]. Escolhendo diversos pares de pontos de contato do disco com um circuito externo, estabeleceu que uma situação favorável ocorre ao conectar-se ao eixo de rotação uma das extremidades do circuito, e a outra à borda do disco. Faraday concretizou assim seu intuito, perseguido desde a descoberta do eletromagnetismo, em 1820, de produzir eletricidade a partir do magnetismo.

A réplica do Disco de Arago construída pelo MINF/UFPA (Fig. 5b) apresentou bom funcionamento, revelando claramente a interação entre a haste magnética e o disco em rotação. Já o Dínamo de Disco revelou-se um dispositivo muito delicado e somente com o auxílio de um multímetro, graduado em sua escala mais sensível, é que a corrente gerada pôde ser percebida, o que nos indicou a necessidade de otimização da réplica construída pelo MINF/UFPA (Fig. 6b). Estas duas réplicas puderam, por sua relativa simplicidade, ser feitas com os recursos e ferramentas de que dispúnhamos. Porém, na medida em que tal prática nos aponta para realizações mais sofisticadas, torna-se desejável a utilização de uma oficina bem equipada para a confecção de réplicas.

\subsection{Abordagens Metodológicas}

Em um ambiente informal de ensino de ciências, a construção de uma atmosfera que estimule o intelecto dos visitantes por meio de situações inovadoras produz um contexto bastante favorável ao aprendizado 34, 35]. Ao explorar as relações mediadorvisitante, visitante-visitante e mediador-visitantesociedade, a construção do conhecimento torna-se mais sutil. Para contribuir com o processo de ensino e de aprendizagem em ciências, as exibições em um museu interativo necessitam de uma estruturação 
lógica básica que deve ser flexível em sua ordenação. Ou seja, apesar de sua flexibilidade e das situações imprevisíveis, algumas características devem ser analisadas e exploradas, como a apresentação de objetivos da visita ao espaço, as interações discursivas, o uso coerente da História da Ciência, a utilização da transdisciplinaridade, a interatividade e a interpretação do erro como um estágio da aprendizagem.

Normalmente, dois tipos principais de situações são presenciadas em ambientes informais de aprendizagem: uma visitação por escolha própria, quase sempre incentivada pela busca de novos ambientes de lazer e/ou instrução, e a visitação induzida, incentivada por professores e programas escolares que procuram uma renovação de ferramentas pedagógicas. Na visitação por escolha própria, apesar da diversidade, o interesse e a participação do público são regulares. Muitos reconhecem os equipamentos com entusiasmo e disposição para captar novas informações e fazer as associações com elementos cotidianos. Nas visitas induzidas, principalmente para um público infanto-juvenil, o interesse deve ser mais enfaticamente estimulado. Este público tende a centrar seus interesses mais em elementos do seu mundo do que em interesses de terceiros [36]. Assim, a relevância da visita deve ser esclarecida e conectada com o cotidiano dos estudantes.

Segundo Griffin [37, para que uma atividade de aprendizagem de estudantes em museus seja eficaz, é de extrema importância que o conteúdo da exibição seja apresentado e relacionado aos conteúdos abordados simultaneamente em sala de aula. Tendo isso em mente, acreditamos que a apresentação de equipamentos que influenciaram descobertas intrinsecamente ligadas ao dia-a-dia destes estudantes, no decorrer do desenvolvimento histórico, promove um ambiente fértil para discussões e novas concepções.

As interações discursivas são constituintes fundamentais para a construção de significados em ambientes de ensino e aprendizagem, sejam estes ambientes formais ou informais. Um crescimento coletivo por meio da associação de perspectivas culturais individuais ocorre quando o estímulo ao diálogo é fomentado, o que também incentiva o respeito para lidar com opiniões divergentes [38. O papel do mediador vai além de introduzir novos termos e ideias do conteúdo central que será trabalhado. Assim, construir diálogos argumentativos que abordem a História da Ciência requer um conhecimento acerca da diversidade cultural dos visitantes. A in- tervenção por meio de abordagens mais descritivas e menos imperativas evitam que o ambiente torne-se repressor, o que contribui até mesmo para que os estudantes menos participativos não se sintam intimidados e possam interagir de forma natural, por meio de questionamentos e comentários, intervindo como agentes transformadores de si mesmos e de suas realidades [39].

Utilizar a História da Ciência como metodologia principal para aprimorar o ensino de ciências, segundo Matthews [40], torna os conceitos abordados mais atraentes para muitos estudantes. Também é importante estar atento para evitar as citações de datas e nomes isolados, a simplificação do passado e a incorporação de outros whiggismos [41] durante a evolução da apresentação. É importante abordar um conteúdo de forma transdisciplinar para contribuir com o processo ensino-aprendizagem. A Física é uma disciplina vista como de extrema complexidade por muitos estudantes, talvez devido à ausência de inovações em sua prática de aprendizagem [42]. A utilização de ferramentas que apresentem seu conteúdo associado a outras disciplinas que integrem as relações homem-homem e homem-natureza pode contribuir para promover o entusiasmo dos estudantes [43].

A interação com o objeto museológico é um diferencial do ambiente museal. As exibições que ocorrem em museus tradicionais, em sua maioria, baseiamse em uma contemplação dirigida de réplicas ou de obras originais. Ao conhecer e manipular um equipamento que possui um cunho histórico, mesmo sendo uma réplica, conexões entre o passado, o presente e o futuro podem ser estabelecidas. Este vínculo temporal auxilia em um melhor aproveitamento da abordagem sócio-histórica e nas justificativas que devem ser apresentadas sobre os objetivos da visita ao museu. $\mathrm{O}$ vínculo temporal tende a relacionar os avanços e as descobertas científicas e tecnológicas do passado com as pesquisas de diversas áreas realizadas atualmente, e que, por sua vez, deve incentivar a reflexão sobre o desenvolvimento futuro da ciência e da tecnologia. Estes três parâmetros de vínculo (passado, presente e futuro) estão diretamente interligados e retratam graus de importância equivalentes apesar de suas particularidades. Segundo Bassalo [44], mesmo sob análises de caráter internalista ou externalista, as particularidades destes vínculos possuem aspectos significativos que justificam a importância do estudo de História da Ciência. 
Existem muitas reflexões sobre o conteúdo a ser abordado em museus interativos e centros de ciência 45]. Diversas discussões concentram-se em indagar se os tópicos apresentados devem abranger conteúdos científicos básicos, ou se, além disso, devem relacionar as exibições com a compreensão pública da pesquisa científica recente. Adotar a abordagem sócio-histórica e apresentar os parâmetros de vínculo temporal, instiga a curiosidade do público acerca do que está sendo produzido em ciência e tecnologia atualmente e induz uma reflexão vocacional para o que os visitantes - sejam estes crianças, jovens ou adultos - ainda podem realizar pelo desenvolvimento científico e tecnológico no futuro, nas mais diversas áreas do conhecimento.

Ao interagir com os equipamentos históricos e realizar experiências dirigidas, o visitante tende a recordar de possíveis situações ocorridas ao longo de sua própria vida. Isto possibilita a construção dos caminhos individuais, muitas vezes a partir de associações próprias com seu cotidiano, que podem proporcionar uma ampliação de seu conhecimento. As limitações observadas em meio às experimentações e discussões também induzem à compreensão do método científico associado aos processos de estabelecer e refutar hipóteses 46.

Em meio às abordagens metodológicas empregadas nas atividades do MINF/UFPA, o erro também é um estágio para a construção do conhecimento. Assim, o foco das interações discursivas estabelecidas está vinculado na formulação de conceitos e concepções abrangentes e não apenas na busca de respostas precisas ou corretas. Quando um estudante desenvolve uma observação confusa ou controversa, é iniciado um processo de ruptura desse obstáculo em busca da reconstrução de um conceito coerente dentro do contexto, o qual pode ser analisado com o auxílio da História da Ciência 47.

\subsection{Atividades Internas e Externas}

Diariamente, estudantes do ensino infantil, fundamental, médio, técnico e superior, assim como o público geral, participam de apresentações nas quais são utilizados experimentos históricos e recursos audiovisuais, no espaço do MINF/UFPA (Fig. 7). Detalhes sobre estas visitações de grupos encontram-se registrados do sítio do MINF/UFPA na internet [12].

Exposições do MINF/UFPA também são realizadas em feiras, mostras e outros eventos de ciência e tecnologia, em parceria com as instituições or-

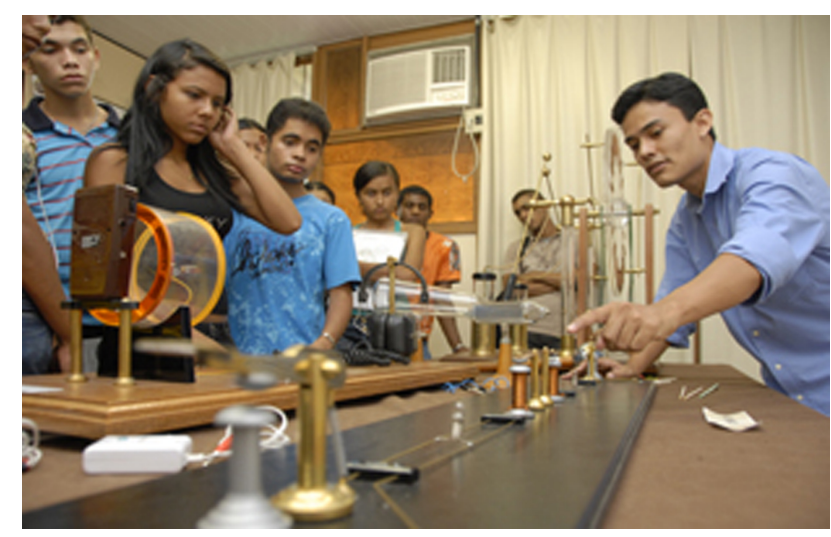

Figura 7: Estudantes do Programa Universidade Aberta (PUA), interagindo com experimentos do MINF/UFPA, no dia 21 de agosto de 2009. Fotografia de Alexandre Moraes.

ganizadoras destes eventos, usualmente vinculados às Secretarias de Estado do Pará e dos municípios paraenses e às universidades públicas (Figs. 8 e 9). Experimentos históricos e pôsteres explicativos do acervo do MINF/UFPA são transportados para o local dos eventos e expostos por monitores em estandes cedidos pela organização. As apresentações externas seguem a mesma metodologia das apresentações internas, porém são abordagens mais sucintas, com duração de alguns minutos por experimento. O público nesses eventos é, em sua maioria, diversificado e rotativo, o que requer a otimização e a adaptação do nível das apresentações, enfatizando conceitos mais básicos acerca dos fenômenos observados. Os pôsteres explicativos, produzidos pela equipe do MINF/UFPA, também auxiliam o público

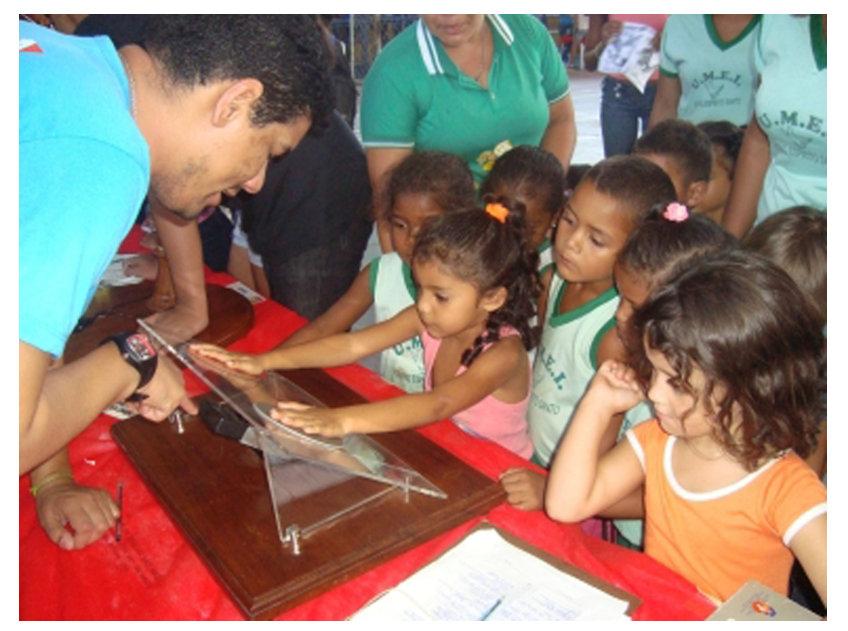

Figura 8: Exposição do MINF/UFPA na Mostra Camillo Vianna de Ciência e Cultura, em São Miguel do Guamá/PA, em 15 de agosto de 2012. 


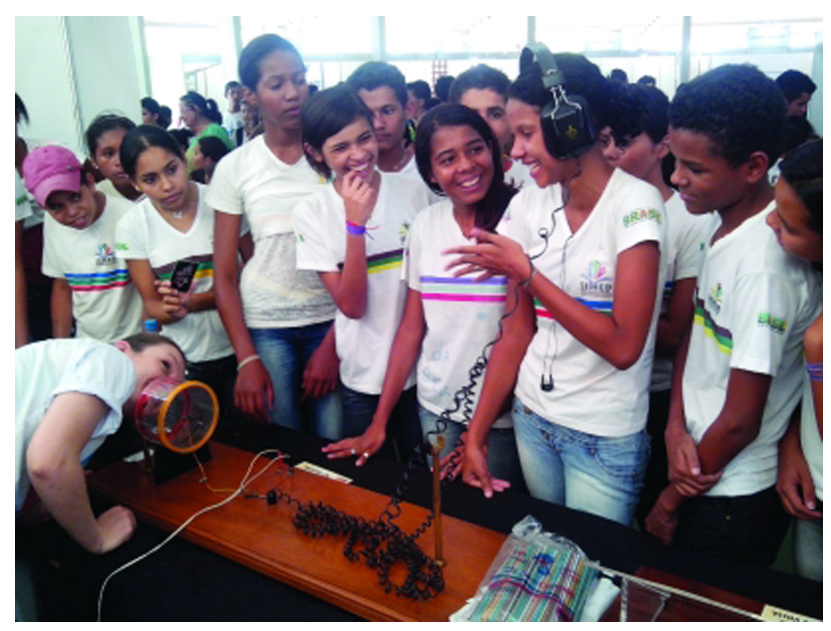

Figura 9: Exposição do MINF/UFPA na Mostra de Ciência, Tecnologia e Inovação para o Desenvolvimento Regional, em Marabá/PA, em 08 de abril de 2014.

em busca de mais informações históricas e científicas sobre os equipamentos.

O MINF/UFPA também oferece oficinas com duração de 30 a 120 minutos, que são realizadas em feiras, mostras e outros eventos de divulgação científica e tecnológica estaduais, regionais e/ou nacionais (Figs. 10 e 11). Adaptadas conforme o nível de escolaridade e faixa etária do público, as oficinas do MINF/UFPA visam divulgar o desenvolvimento científico por meio de diálogos sobre a História da Ciência com auxílio de recursos audiovisuais (vídeos com trechos de filmes e documentários, imagens históricas, etc.) e experimentos que ilustrem o contexto de descobertas e invenções na ciência. Nas oficinas, os materiais utilizados passam por um processo prévio de estruturação para evitar que o público tenha que manusear objetos potencialmente perigosos, prevenindo possíveis acidentes, além de facilitar na montagem e de otimizar o tempo para o melhor aproveitamento da atividade.

\section{Considerações Finais}

Neste trabalho abordamos a difusão e popularização da História da Ciência em ambientes informais de educação, tomando como base o papel do Museu Interativo da Física (MINF) da UFPA na divulgação científica para a Amazônia brasileira. Após uma breve introdução sobre o tema, apresentamos o MINF/UFPA, descrevendo seu acervo, que inclui réplicas de experimentos históricos construídos pela própria equipe do MINF/UFPA, bem como as abordagens metodológicas e as atividades internas e ex-

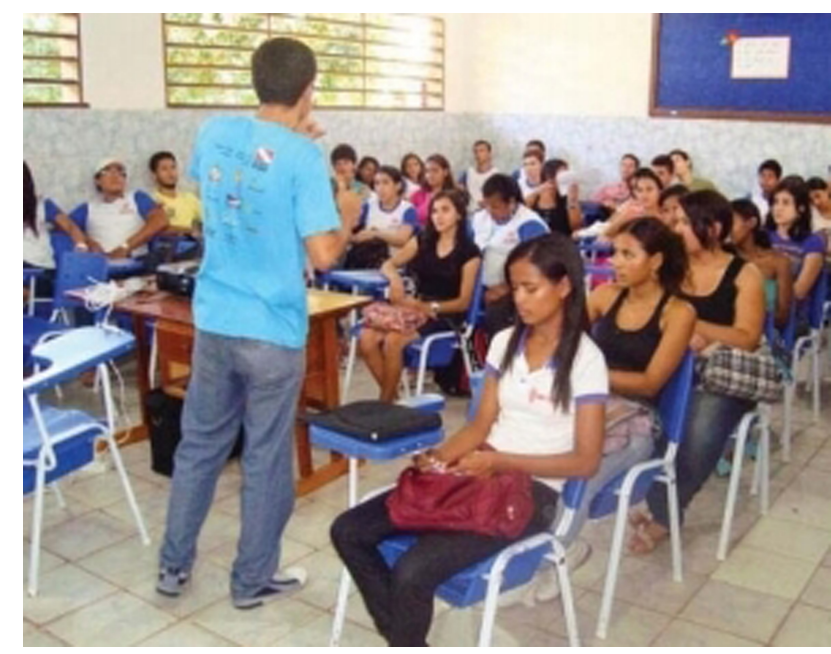

Figura 10: Seminário do MINF/UFPA para estudantes da rede pública de ensino, ministrado durante a Mostra Camillo Vianna de Ciência e Cultura em Paragominas/PA, em 25 de maio de 2012.

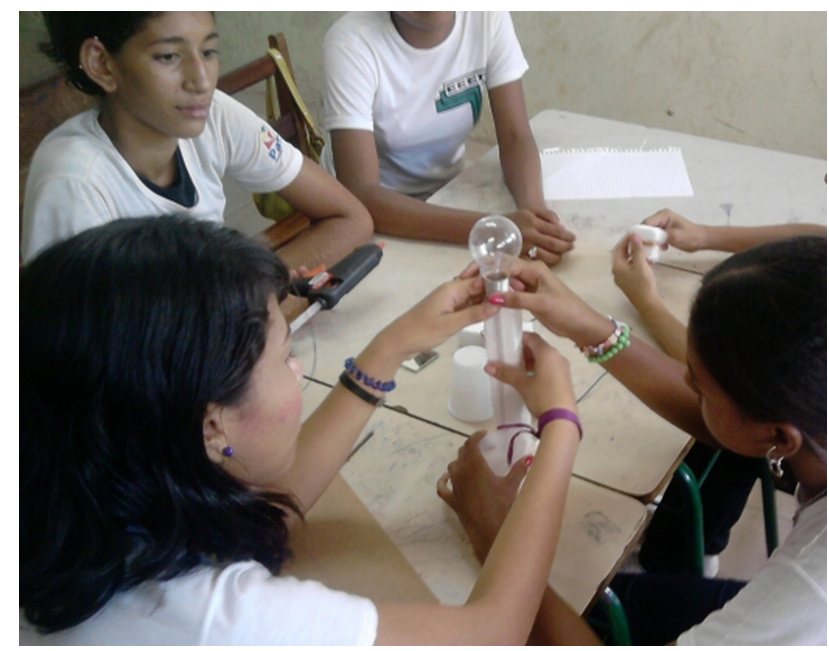

Figura 11: Oficina do MINF/UFPA realizada com estudantes da rede pública de ensino de Ananindeua/PA, em 17 de novembro de 2010.

ternas realizadas, incluindo oficinas, seminários e demonstrações interativas, todas objetivando relacionar os avanços científicos com o contexto sóciohistórico no qual foram desenvolvidos.

Desde sua fundação, em 2008, o MINF/UFPA já atendeu mais de 40.000 pessoas durante suas atividades internas e externas. Entre esses atendimentos, um número aproximado de 35.000 pessoas corresponde às apresentações externas em mostras, feiras e eventos de divulgação científica e tecnológica em 29 municípios do Estado do Pará (e 3 ilhas na região metropolitana de Belém), integrando 4 das 6 mesorregiões do Estado [48. A área percorrida 
nestes atendimentos é equivalente a de países inteiros como, por exemplo, a Itália e a Polônia, sendo as condições de deslocamento em nada comparáveis à infraestrutura rodoviária, ferroviária e fluvial de tais países. As ações promovidas pelo MINF/UFPA têm também incentivado a produção de trabalhos e monografias sobre História da Ciência [28], sua divulgação na Amazônia brasileira [48] e suas abordagens metodológicas [49].

O MINF/UFPA utiliza as abordagens aqui apresentadas com o objetivo de desmistificar uma visão superficial (e muitas vezes errônea) do desenvolvimento científico, lançando mão da História para expor uma ciência de caráter contextualizado e realista.

Esperamos que iniciativas semelhantes ao MINF/ UFPA, que visem explorar relações entre as diversas ciências em um ambiente informal de aprendizagem, possam ser cada vez mais desenvolvidas, tanto na Amazônia brasileira, quanto no Brasil como um todo. Estas iniciativas não só contribuem para a alfabetização científica, como também para a orientação vocacional de jovens e adultos, para a qualificação de professores e futuros docentes, e refletem positivamente na construção de um país com maior acesso a uma educação de qualidade e menos desigual.

\section{Agradecimentos}

Os autores são gratos a José Maria Filardo Bassalo, pioneiro amazônida na difusão da História da Ciência, Aníbal Fonseca de Figueiredo Neto, Newton Martins Barbosa Neto, Rodrigo Pinheiro Vaz e Victor Façanha Serra, bem como a todos os professores, bolsistas e voluntários da equipe do MINF/UFPA. O autores também são gratos à Faculdade de Física, ao Instituto de Ciências Exatas e Naturais e à PróReitoria de Extensão da UFPA, pelo incentivo ao MINF/UFPA, desde a sua fundação. Gostaríamos também de registrar nossos agradecimentos ao Conselho Nacional de Desenvolvimento Científico e Tecnológico $(\mathrm{CNPq})$ e à Financiadora de Estudos e Projetos (FINEP), pelo apoio financeiro.

\section{Referências}

[1] Sítio eletrônico da Cité des Sciences \& de L'industrie. Disponível em http://www.cite-sciences.fr, acesso em 5/4/2016.

[2] Sítio eletrônico do Museo de Ciencias CosmoCaixa. Disponível em http://obrasocial.lacaixa. es/nuestroscentros/cosmocaixabarcelona/ cosmocaixabarcelona_es.html, acesso em $5 / 4 / 2016$.

[3] Sítio eletrônico do Centrum Nauki Kopernik. Disponível em http: //www.kopernik.org.pl, acesso em $5 / 4 / 2016$.

[4] Sítio eletrônico do Museo Participativo de Ciencias. Disponível em http://www.mpc.org.ar acesso em $5 / 4 / 2016$.

[5] A. Gaspar, Caderno Brasileiro de Ensino de Física 9, 157 (1992).

[6] Sítio eletrônico do Museu Paraense Emílio Goeldi. Disponível em http://www.museu-goeldi $\mathrm{br} /$, acesso em 05/4/2016.

[7] L.C.B. Crispino, V.B. Bastos e P.M. Toledo, As Origens do Museu Paraense Emílio Goeldi: Aspectos Históricos e Iconográficos (1860-1921) (Paka-Tatu, Belém, 2006), p. 69.

[8] Sítio eletrônico do Museu de Ciência da Amazônia. Disponível em http://museudaamazonia.org.br, acesso em 5/4/2016.

[9] Sítio eletrônico da Estação Ciência. Disponível em http://prceu.usp.br/centro/estacaociencia, acesso em 12/3/2016.

[10] Sítio eletrônico da Seara da Ciência. Disponível em http://www.searadaciencia.ufc.br, acesso em $12 / 3 / 2016$.

[11] Sítio eletrônico do Projeto Casa da Física. Disponível em http://projetocasadafisica. blogspot.com acesso em 12/3/2016.

[12] Sítio eletrônico do Museu Interativo da Física. Disponível em http://www.minf .ufpa.br, acesso em $10 / 4 / 2016$.

[13] Sítio eletrônico do Laboratório de Demonstrações. Disponível em http://www.labdemon.ufpa.br, acesso em 20/2/2016.

[14] M.R. Matthews, Caderno Catarinense de Ensino de Física 12, 164 (1995).

[15] A discussão que Matthews realiza na Ref. 14 possui aspectos centrados em como uma ideologia sexista pode vir a afetar a ciência e, apesar de servir como parâmetro para novas abordagens e concepções utilizadas pelo MINF/UFPA, transcende ao escopo deste trabalho.

[16] R. Moraes, Experimentação no Ensino de Ciências. Projeto Melhoria da Qualidade de Ensino - Ciências 1ํㅡ. Grau. Governo do Estado do Rio Grande do Sul (1993).

[17] S. Cazelli, M. Marandino e D.C. Studart, in: Educação e Museu: A Construção Social do Caráter Educativo dos Museus de Ciência, organizado por G. Gouvêa e M. Marandino (Access, Rio de Janeiro, 2003), p. 83-106.

[18] M. Van-Praët, in: Educação e Museu: A Construção Social do Caráter Educativo dos Museus de Ciência, organizado por G. Gouvêa e M. Marandino (Access, Rio de Janeiro, 2003), p. 47-62. 
[19] Sítio eletrônico da Ciência Prima. Disponível em http://www.cienciaprima.com.br acesso em $20 / 2 / 2016$.

[20] Sítio eletrônico do Museu Catavento - Espaço Cultural da Ciência. Disponível em http://www. cataventocultural.org.br, acesso em 20/2/2016.

[21] C.P. Magnaghi e A.K.T. De Assis, Caderno Brasileiro de Ensino de Física 25, 118 (2008).

[22] J.M.F. Bassalo, in: Crônicas da Física. Tomo 1, editado por J.M.F. Bassalo (EDUFPA, Belém, 1987), p. 274-283.

[23] M.V. Guedes, Revista Electricidade 397, 145 (1999).

[24] Sítio eletrônico da Comune di Como - Assessorato Cultura. Disponível em http://cultura.comune.como.it/wp-content/ uploads/2013/06/collezioni1.jpg acesso em $5 / 4 / 2016$.

[25] A.P. Morgan, The Boy Electrician (Lothrop, Lee \& Shepard Company, Boston, 1929), p. 46.

[26] J. Wimshurst, The London, Edinburgh, and Dublin Philosophical Magazine and Journal of Science 31, 507 (1891).

[27] H.M. Aguilar, Latin-American Journal of Physics Education 8, 100 (2014).

[28] R.P. Vaz, As Pesquisas de Faraday que o Levaram à Descoberta da Indução Eletromagnética. Trabalho de Conclusão de Curso, Faculdade de Física, Universidade Federal do Pará, Belém, 2013.

[29] M.P. Souza Filho e J.J. Caluzi, Revista Brasileira de Ensino de Física 31, 1603 (2009).

[30] J.M.F. Bassalo, Nascimentos da Física (3500 a.C.1900 a.D.) (EDUFPA, Belém, 1996), p. 311.

[31] J. Jamin, Cours de Physique de l'École Polytechnique: 3 (Mallet-Bachelier, Paris, 1861), p. 301.

[32] E. Alglave and J. Boulard, The Electric Light: Its History, Production, and Applications (D. Appleton and Company, New York, 1884), p. 224.

[33] M. Faraday, Philosophical Transactions of the Royal Society of London (1776-1886) 122, 125 (1832).

[34] A. Gaspar, Museus e Centros de Ciências - Conceituação e Proposta de um Referencial Teórico. Tese de Doutorado, Faculdade de Educação, Universidade de São Paulo, São Paulo, 1993.

[35] L.S. Vygotsky, Pensamento e Linguagem (Martins Fontes, São Paulo, 2008), p. 1-10.

[36] G. Fourez, Investigações em Ensino de Ciências 8, 109 (2003).

[37] J. Griffin, International Journal of Science Education 20, 655 (1998).

[38] E.F. Mortimer and P. Scott, Investigações em ensino de ciências 7, 283 (2002).

[39] F. Antunes e R.F. Salvi, in: VII Encontro Nacional de Pesquisa em Educação em Ciências, Florianópolis (2009).

[40] M.R. Matthews, Science Teaching: The Role of History and Philosophy of Science (Routledge, New York, 1994), p. 7.
[41] N.M.V. Bizzo, Em aberto 11, 29 (1992).

[42] R. Tavares, Revista Conceitos 55, 55 (2004).

[43] A. Cachapuz, J. Praia e M. Jorge, Ciência \& Educação 10, 363 (2004).

[44] J.M.F. Bassalo, in: J.M.F. Bassalo, Crônicas da Física. Tomo 4 (EDUFPA, Belém, 1994), p. 15211537.

[45] H. Field, and P. Powell, Public Understanding of Science 10, 421 (2001).

[46] L.H.A. Silva e L.B. Zanon, in: R.P. Schnetzler e R.M.R. Aragão, Ensino de Ciências: Fundamentos e Abordagens (CAPES/UNIMEP, Piracicaba, 2000), p. 120-153.

[47] A.R.C. Lopes, Enseñanza de las Ciencias 11, 324 (1993).

[48] J. Caldas, Museu Interativo da Física da UFPA: Ação Educativa com Ênfase em Divulgação e Popularização da História e da Filosofia da Ciência para o Ensino de Fúsica. Trabalho de Conclusão de Curso, Instituto de Ciências Exatas e Naturais, Faculdade de Física, Universidade Federal do Pará, Belém, 2015.

[49] K.L. Silva, O Museu Interativo da Física e a Prática Metodológica de Experimentos Históricos no Ensino de Física para Conteúdos de Eletricidade. Trabalho de Conclusão de Curso, Instituto de Ciências Exatas e Naturais, Faculdade de Física, Universidade Federal do Pará, Belém, 2015. 